\title{
The stress-induced protein NUPR1 orchestrates protein translation during ER-stress by interacting with elF2 $\alpha$
}

Maria Teresa Borrello ${ }^{1}$, Patricia Santofimia-Castaño ${ }^{1}$, Marco Bocchio ${ }^{2}$, Angela Listi ${ }^{1}$, Nicolas Fraunhoffer ${ }^{1}$, Philippe Soubeyran ${ }^{1}$, Eric Chevet $^{3}$, Christopher Pin ${ }^{1,4}$, Juan Iovanna ${ }^{1}$

${ }^{1}$ Centre de Recherche en Cancérologie de Marseille, INSERM U1068, CNRS UMR 7258, AixMarseille Université and Institut Paoli-Calmettes, Parc Scientifique et Technologique de Luminy, 13288 Marseille, France;

2 INMED (INSERM U1249), Aix-Marseille University, Turing Center for Living Systems, Parc Scientifique de Luminy, 13273, Marseille, France;

${ }^{3}$ INSERM U1242, Proteostasis and Cancer Team, Chemistry Oncogenesis Stress Signaling, Université de Rennes 1, Rennes, France;

${ }^{4}$ Departments of Pediatrics, Oncology, and Physiology and Pharmacology, Schulich School of Medicine, University of Western Ontario, Children's Health Research Institute, London, ON, Canada N5C 2V5;

Corresponding author address: Juan lovanna, email: juan.iovanna@inserm.fr.; Borrello Maria Teresa (maria-teresa.borrello@inserm.fr), Centre de Recherche en Cancérologie de Marseille (CRCM), INSERM U1068, CNRS UMR 7258, Aix-Marseille Université and Institut PaoliCalmettes, Parc Scientifique et Technologique de Luminy, 163 Avenue de Luminy, 13288 Marseille, France. Phone +33-491828803; Mobil Phone +33-760988158; Fax +33-491 826083. 


\begin{abstract}
NUPR1 is a stress response protein overexpressed upon cell injury in virtually all organs including the exocrine pancreas. Despite NUPR1's well established role in the response to cell stress, the molecular and structural machineries triggered by NUPR1 activation remain largely unknown. In this study, we uncover an important role for NUPR1 in participating in the unfolded protein response pathway and the endoplasmic reticulum stress response. Biochemical results, confirmed by ultrastructural morphological observation, revealed alterations in the UPR in acinar cells of germline-deleted NUPR1 murine models, consistent with the inability to restore general protein translation. Bioinformatical analysis of NUPR1 interacting partners showed significant enrichment in translation initiation factors, including eukaryotic initiation factor (elF) $2 \alpha$. Co-immunoprecipitation and proximity ligation assays both confirmed interaction between NUPR1 and elF2 $\alpha$ and its phosphorylated form (p-elF2 $\alpha$ ). Our. Moreover, our data also suggest loss of NUPR1 in cells results in maintained elF2 $\alpha$ phosphorylation and evaluation of nascent proteins by (pelF2 $\alpha$ ), and click chemistry revealed that NUPR1-depleted PANC-1 cells displayed a slower post stress protein translational recovery compared to wild-type. Combined, this data proposes a novel role for NUPR1 in the integrated stress response pathway, at least partially through promoting efficient PERKbranch activity and resolution through a unique interaction with elF2 $\alpha$.
\end{abstract}

Keywords: NUPR1, Unfolded Protein Response, ER-stress, elF2 $\alpha$, protein translation 


\section{Significance}

In the pancreas, NUPR1 is required for a resolution of the ER stress response. During ER stress response, NUPR1 binds both elF2 $\alpha$ allowing for its dephosphorylation and restoration of new protein synthesis. 


\section{Highlights}

Biochemical analysis revealed a general reduction in the protein expression of downstream mediators of the unfolded protein response in the pancreas of mice lacking Nupr1. This finding suggests a novel role for NUPR1 in the UPR/ER stress response.

Ultrastructural analysis of pancreata revealed reduced morphological alterations in tunicamycin-treated $\mathrm{Nupr}^{-1-}$ mice compared to $\mathrm{Nupr} 1^{+/+}$mice consistent with a maintained block in general protein translation.

Co-immunoprecipitation of tagged NUPR1 confirmed a novel interaction with elF2 $\alpha$. Depletion of NUPR1 prolonged phosphorylation of elF2a, suggesting it may be involved in attenuation of the PERK branch of the UPR.

NUPR1-depleted PANC-1 cells displayed a slower recovery of protein translation following UPR activation 


\section{Introduction}

NUPR1, also known as p8 or Com1, is an intrinsically-disordered protein first identified during the onset of pancreatitis [1]. We and others demonstrated NUPR1 is transiently induced in almost all organs and cells in response to a variety of injuries [2-6] including minimal stresses such as the renewal of culture medium [7]. While it is clear NUPR1 acts as an essential element during the stress cell response, protecting cells from genotoxic or oxidative injury [811], the mechanisms by which NUPR1 acts still need to be elucidated. The highest expression of NUPR1 has been reported in pancreatic acinar cells following induction of pancreatitis. Acinar cells are highly enriched for endoplasmic reticulum (ER) due to their having the highest rate of protein synthesis among all cell types [12,13]. A major function of the ER involves folding and post-translational modification of secreted and integral membrane proteins. Also, the ER maintains homeostasis between folded and unfolded proteins $[14,15]$ and disturbance of these physiological ER activities leads to a cell stress response implicated in a variety of pathological states $[14,16,17]$. Several pieces of evidence indicate NUPR1 is involved in the onset of ER stress but its role in this context remains largely unexplored $[18,19]$.

ER stress can be activated by a number of events including accumulation of unfolded proteins in the ER, subsequently triggering several signaling pathways that, together, are termed the unfolded protein response (UPR). The ultimate goal of the UPR is to resolve homeostatic imbalance between folded and unfolded proteins. If protein homeostasis is not restored, the UPR triggers apoptosis to safely dispose of damaged cells. The UPR is comprised of three main branches - PKR-like ER kinase (PERK), inositol-required enzyme 1 (IRE1) and activation transcription factor 6 (ATF6). In the absence of stress, these molecules are bound to the chaperone BiP (GRP78 or HSPA5). When excessive protein load occurs, BiP dissociates from PERK, IRE1 and ATF6 leading to their activation [20]. Activation of PERK leads to phosphorylation of the eukaryotic initiation factor $2 \alpha$ (elF2 $\alpha$ ), which is a critical regulator of protein translation. Phosphorylated elF2 $\alpha$ prompts a dramatic reduction in protein translation to limit cellular amino-acid consumption. However, several mRNA transcripts elude the translation block, including Activating Transcription Factor 4 (ATF4). ATF4 increases cell survival by promoting the expression of genes involved in protein folding, amino-acid import and biosynthesis of aminoacyl-transfer RNAs [21]. When protein homeostasis is restored, GADD34/PPP1R15A, which is activated by ATF4, promotes elF2 $\alpha$ dephosphorylation, thereby restoring normal protein synthesis [22]. Prolonged or excessive ER stress activation leads to programmed cell death, mainly mediated by the activation of the CCAAT/enhancer binding protein (C/EBP) homologous protein (CHOP) [16,22], which promotes apoptosis via the intrinsic mitochondrial pathway. 
The goals of this study were to determine if the absence of NUPR1 altered the ER stress response and UPR in the pancreas and determine a possible mechanism by which NUPR1 affected this pathway. We report that NUPR1 constitutes an important element of the UPR activation. Our data shows in the absence of NUPR1 in the pancreas, phosphorylation of elF2 $\alpha$ is maintained, thereby preventing restoration of protein translation and, likely, contributing to increased tissue damage. We provide evidence that NUPR1's directly interacts with elF $2 \alpha$, and may be required for its dephosphorylation and restoration of proper protein translation. This is a completely novel function for NUPR1 and, for the first time, links these two critical factors involved in the integrated stress response.

\section{Results}

\section{Biochemical evaluation of ER-stress activators in pancreatic acinar cells of $\mathrm{Nupr}^{+/+}$} and Nupr $^{-/-}$mice

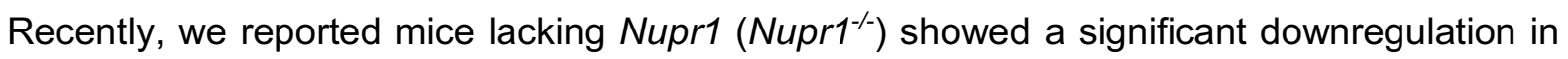
genes related to ER stress in the pancreas [18] suggesting NUPR1 is necessary for mediating a correct UPR activation. To test the importance of NUPR1 in the onset of the ER-stress response, pharmacological activation of stress was initiated by a single injection of

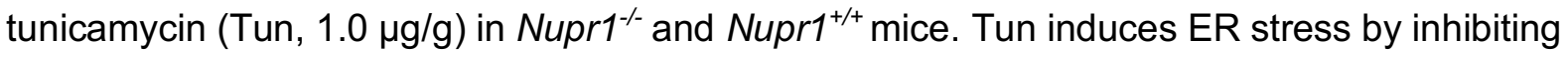
protein $\mathrm{N}$-Glycosylation, thereby preventing correct protein folding [23]. Sixteen hours after Tun administration, whole pancreatic protein extracts were collected and the expression levels of the major UPR mediators of the PERK and IRE1- $\alpha$ branches evaluated by western blot and qPCR (Figure 1). PERK accumulation and phosphorylation appeared similar between the two genotypes. Consistent with activation of PERK signaling, increased expression of ATF4 was observed in both $\mathrm{Nupr}^{-/-}$and Nupr1 ${ }^{+/+}$following activation of cell stress (Figure 1). However, the increase in ATF4 expression was reduced in Nupr1/- mice at both protein and mRNA levels (Figure 1G) compared to Nupr $1^{+/+}$tissue following Tun injection $(p<0.0001)$. Reduced ATF4 function was supported by the absence of CHOP protein in Nupr1 ${ }^{-/}$pancreata (Figure $1 \mathrm{~A}, \mathrm{~B})$. Interestingly, while we observed reduced induction of Chop mRNA expression in Nupr $1^{-/}$mice compared to Nupr $1^{+/+}$after stress (effect of Tun: $p<0.0001$; effect of genotype $p$ $<0.0001$; interaction $p<0.0001$; Nupr1 ${ }^{+/+}$vs Nupr1 ${ }^{-/-}$in Tun condition: $p<0.0001$, post hoc Sidak test, $n=6$ ), an increase in Chop mRNA was still observed (Figure 1G), suggesting protein translation may be affected. Similar analysis of another ATF4 target, Gadd34, indicated lower expression in $\mathrm{Nupr}^{-/ /}$pancreata compared to $\mathrm{Nupr}^{+/ /+}$after stress induction. Since GADD34 is involved in a negative feedback loop to reduce PERK signaling, these findings suggest a possible delay in mechanisms involved of the resolution of ER-stress in Nupr1\% 
The phosphorylation of elF $2 \alpha$ is a critical step in the cellular stress response, mediating a protein synthesis shut-off and GADD34 is directly involved in its dephosphorylation. Given reduced GADD34 expression, we next measured the levels of p-elF2 $\alpha$ up to 24 hours following Tun injection (Figure 1C,D). Three hours following Tun treatment similar levels of p-elF2 $\alpha$ are observed in $\mathrm{Nupr}^{+/+}$and Nupr1/- mice. However, at both 6 and 24 hours into Tun treatment, the level of $p$-elF2 $\alpha$ is significantly higher in Nupr1/- tissue, revealing a possible delay in the mechanism of ER-stress termination in $\mathrm{Nupr}^{1 /}$.

Biochemical examination of IRE $1 \alpha$ branch activation showed post-stress accumulation of IRE1 $\alpha$ and phospho (p) IRE1 $\alpha$ with no significant variation in both genotypes (Figure 1E-F). However, western blot analysis showed pancreatic expression of the chaperone BiP was almost halved in $\mathrm{Nupr}^{-/-}$mice compared to $\mathrm{Nupr}^{+/+}$mice $(\mathrm{n}=3)$. Expression of the BiP mRNA showed a consistent downregulation in $N u p r 1^{-/-}$mice compared to Nupr1 ${ }^{+/+}$littermates $(\mathrm{n}=6)$. For both protein and mRNA, two-way ANOVA analysis revealed a significant effect of Tun ( $p$ $<0.0001$ for protein expression and $p<0.001$ for mRNA). Subsequent comparisons uncovered a significant difference in BiP between $\mathrm{Nupr}^{+/+}$and $\mathrm{Nupr}^{-/-}$mice after Tun administration ( $p<0.0001$ for protein and $p=0.0228$ for mRNA, post hoc Sidak test) but not in control conditions.

$\mathrm{BiP}$ is a stress sensor of the UPR and an integral part of the ER quality control system. Upon UPR initiation, the translational efficiency of BiP is normally increased by $2-3$ fold and it is regulated by several overlapping mechanisms [24]. Therefore, downregulation of BiP protein and mRNA expression could be correlated with a faulty UPR machinery in Nupr1\% mice. Similar levels of total IRE1 $\alpha, p-I R E 1 \alpha$ and spliced XBP1 (XBP1s) protein were observed in both $\mathrm{Nupr}^{+/+}$and $\mathrm{Nupr}^{-/-}$treated mice suggesting an effective activation of the IRE1a branch occurred. However, a significant difference was detected between the two genotypes when examining Xbp1s mRNA levels (Figure 1G). The increase in Xbp1s mRNA induced by stress in Nupr $1^{-/}$mice was significantly lower compared to Nupr $1^{+/+}$mice (effect of Tun: $p<0.0001$; effect of genotype $p=0.003$, with no interaction between the two factors; Nupr $1^{+/+}$vs Nupr $1^{-/}$ in Tun condition: $p<0.0001$ post hoc Sidak test, $\mathrm{n}=6$ ). To validate the decrease of $X b p 1 s$ in Nupr ${ }^{-/}$models, we evaluated Erdj4 mRNA expression, a known target of XBP1s transcriptional regulation [25]. Consistent with reduced XBP1s function, Erdj4 expression was

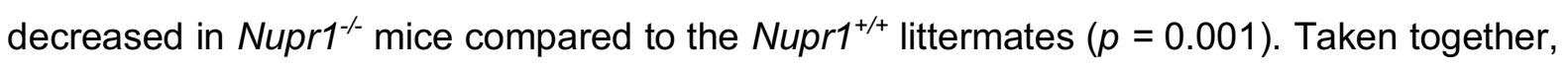
these results indicate the absence of NUPR1 leads to a compromised activation of the UPR. 


\section{NUPR1-deficiency could prevent initial ultrastructural alterations in murine pancreatic acinar cells after Tunicamycin induced cell stress}

To determine the effects of deleting Nupr1 on acinar cell morphology, we examined ultrastructural modifications of the ER in $\mathrm{Nupr}^{+/+}$and Nupr1 $1^{-/-}$mice $16 \mathrm{~h}$ or $36 \mathrm{~h}$ post-Tun treatment using transmission electron microscopy. Representative micrographs indicate nontreated exocrine pancreatic cells (Figures $2 \mathrm{~A}$ and $2 \mathrm{~B}$ ) present with a normal ER, structurally ordered into thin, densely packed cisternae covered with ribosomes in both genotypes (arrows in insets of Figure 2A and 2B). Overall, cell ultrastructure was normal in Nupr1-- mice. Acinar cells showed regular polarized organization with visible mononucleated cells $(\mathrm{Nu})$ and electron dense zymogen granules (zy). Sixteen hours post-Tun injection, acinar cells in Nupr1+/+ mice displayed dilated and expanded ER (Figure 2C and inset) with an almost complete loss of associated ribosomes in the perinuclear area and fewer electron dense zymogen granules. Expanded ER cisternae are a cellular hallmark of the UPR as ER membranes expand to alleviate the stress due to an excessive load of misfolded proteins. Increasing ER volume decreases the relative concentration of unfolded protein intermediates, increases the time for protein folding, and avoids aggregate formation [26]. While a decrease in zymogen granules was detected in Nupr1\% pancreata (Figure 2D), even $36 \mathrm{~h}$ after Tun treatment, little to no expansion of the ER was observed. As time progressed, damage to the ER was more aggravated in $\mathrm{Nupr}^{+/+}$mice, becoming fragmented (Figure 2E). Such ER abnormalities were observed in $\mathrm{Nupr}^{+/+}$samples in more than $40 \%$ of the analyzed acinar cells (12/30 cells from ten randomly selected fields of acquisition). Conversely, such ER dilation was almost completely absent in Nupr1/- samples (Figure $2 \mathrm{~F}$ ).

The acinar cell phenotype observed in $\mathrm{Nupr}^{-/-}$mice suggests that translation of proteins may be generally affected in response to stress in these mice. Since an absence of NUPR1 is correlated to reduced Gadd34 expression and limited expansion of the ER in Nupr1/- mice, we speculated NUPR1 is required for restoration of protein synthesis. To test this hypothesis, acinar cells were isolated and assessed in culture (Figure 3A). This process activates the UPR [27]. Morphological analysis of isolated acinar cells showed no obvious difference between $\mathrm{Nupr}^{+/+}$and Nupr1/- acini (Figure 3B). Quantification of amylase levels, however, showed a significant decrease in amylase protein in Nupr1\% cells (Figure 3C; $p<0.05$, post hoc Sidak test), suggesting protein translation was reduced in these animals. It is possible however, that lower amylase levels could reflect increased exocytosis in the absence of NUPR1. To examine this possibility, we measured secretion of amylase in ex-vivo pancreatic acini from Nupr1 ${ }^{+/+}$ and Nupr1\% mice (Figure 3D). Following 30 min incubation with increasing concentrations of cerulein (analogue of cholecystokinin [28]) media amylase levels revealed a dose-dependent 
response for both genotypes (Figure 3D, effect of caerulein: $p<0.012$, two-way ANOVA). Noteworthy, media-amylase levels were significantly lower in Nupr1/- acinar cultures compared to $\mathrm{Nupr}^{+/+}$cultures (Figure 3D, $p<0.0001$, two-way ANOVA) supporting a model in which decreased amylase levels were due to either reduced translation or increased degradation in $\mathrm{Nupr}^{-1-}$ acini.

\section{Identifying the role of NUPR1 during ER stress response}

Based on these observation, the loss of NUPR1 appears to affect restoration of protein translation in response to ER stress. To identify the molecular mechanisms through which NUPR1 may regulate the UPR, we performed immunoprecipitation for NUPR1 to determine putative interacting proteins. Flag-tagged NUPR1 was expressed in MiaPaCa-2 cells (Supplementary Figure 1) and immunoprecipitated 24 hours later under either normal conditions or following induction of ER-stress by glucose starvation or addition of $1 \mu \mathrm{M}$ thapsigargin (TPS; Figure 4). NUPR1-associated proteins were next identified by mass spectrometry (MS) resulting in 656 putative NUPR1-interacting proteins under normal conditions (Supplementary Table 1), and 1152 or 828 interacting proteins under glucosestarvation (Supplementary Table 2) and TPS conditions (Supplementary Table 3), respectively (Figure 4A). 577 proteins were common to all conditions, with 7 (non-treated), 365 (glucosestarvation) and 77 proteins (TPS) specific to the various conditions (Figure 4A). Bioinformatic analysis using the String protein-protein interaction database showed significant enrichment in translation initiation factors, supporting a model in which NUPR1 affects protein translation. Twenty-two out of a total of 142 proteins directly involved in translation initiation were identified under unstressed (non-treated) conditions ( $p=4.14 \mathrm{e}-07$; Table 1). As expected for a role in protein translation during cellular stress, the number of NUPR1-interacting proteins increased to $73(p=5.19 \mathrm{e}-36)$ in glucose-starvation and $45(p=4.76 \mathrm{e}-21)$ in TPS-treated cells (Table 1$)$. This suggest an expanded role for NUPR1 in translational regulation during ER stress.

The NUPR1 interactome included many translation initiation factors, which increased upon ER stress induction and included elF2 $\alpha$ (elF2S1), elF2 $\beta$ (elF2S2), and elF2 $\gamma$ (elF2S3) (Figure $4 B$ ). These findings suggest a novel function for NUPR1 and provide a unique link between two important stress response proteins. Since our initial findings imply the levels of $p$-elF2 $\alpha$ are increased in Tun-induced Nupr1 ${ }^{-/}$acinar tissue, we decided to confirm this interaction. First, co-immunoprecipitation was performed following expression of a GFP-tagged NUPR1 in MiaPaCa-2 cells (Figure 4C). The interaction between NUPR1 and elF2 $\alpha$ was confirmed in non-treated cells showing that NUPR1 will bind elF2 $\alpha$ even under non-stressed conditions. Upon glucose starvation and TPS treatment, this interaction was maintained and even 
increased in the presence of TPS, confirming mass spectrometry data. Next, we performed the reverse co-IP, pulling down GFP-tagged NUPR1 using elF2 $\alpha$ antibody (Figure 4D). To show this interaction took place within the cell, the association between NUPR1 and pelF2 $\alpha /$ elF2 $\alpha$, examined using a proximity ligation assay (PLA, Duolink ${ }^{\circledR}$ ), which identifies molecular complexes that occur at distances $<16 \AA$ (Figure 5). Confocal fluorescent microscopy analysis revealed PLA positive foci under all conditions, suggesting NUPR1 interacts with elF2 $\alpha$ independent of cell stress. Importantly, this interaction is extranuclear, which would be expected for a direct interaction with elF2 $\alpha$ and p-elF2 $\alpha$, and is the first direct evidence of an extra-nuclear function for NUPR1. PLA also revealed increased interaction following TPS treatment or glucose starvation (GS), with NUPR1-eIF2 $\alpha$ and NUPR1-p-eIF2 $\alpha$ interactions remaining in the perinuclear area (Figure $5 \mathrm{~A}$ and $5 \mathrm{C}$ ). These observations confirm NUPR1 interacts with both elF2 $\alpha$ and p-eIF2 $\alpha$ and ER stress increases or stabilizes the interaction. Combined, our data suggests a novel role for NUPR1 regulating the translational machinery during ER stress.

\section{NUPR1-depletion enhances elF2 $\alpha$ phosphorylation and delays the translational recovery after stress induction}

So far, our data revealed that NUPR1 interacts with elF2 $\alpha$ both in its phosphorylated and unphosphorylated forms, and this interaction may contribute to alleviating cell stress in acinar cells. The maintenance of high levels of $p$-elF2 $\alpha$ in Nupr $1^{-/}$acini propose a models where NUPR1 would contribute directly or indirectly to the dephosphorylation of elF2 $\alpha$ as a mechanism to allow restoration of protein translation. To test this model, we examined phosphorylation of elF2 $\alpha$ in response to ER stress response in PANC-1 cells $\left(N U P R 1^{+/+}\right)$or NUPR1-null cells (NUPR1/-), generated by CRISPR/Cas9 deletion of NUPR1 [29]. Treatment with $1 \mu \mathrm{M}$ of TPS for up to 24 hours showed $N U P R 1^{-/}$cells maintained higher levels of $p$-elF2 $\alpha$ compared to $N U P R 1^{+/+}$cells (Figure 6A,B). The results prompt us to investigate whether the absence of NUPR1 interferes with expression of downstream effectors of elF2 $\alpha$ signaling, including CHOP and ATF4. Consistent with our in vivo pancreatic data, NUPR1-- cells showed delayed and reduced expression of ATF4 and CHOP compared to $N U P R 1^{+/+}$cells, which show increased expression of these markers within 6 hours of TPS treatment. RT-qPCR results confirmed reduced expression of both $C H O P$ and GADD34 mRNAs at all time points in NUPR $1^{-/}$cells (Figure 6D), consistent with a deficit in PERK/elF2 $\alpha$ signaling. At later stages of stress, GADD34 participates in elF2 $\alpha$ dephosphorylation to revert the protein translation shut off. The hindered expression of UPR markers such as CHOP and ATF4 in in vivo and in vitro NUPR1 loss of function models could be therefore a direct cause of a sustained phosphorylation of elF2 $\alpha$. By expressing lower levels of GADD34 mRNA expression at all time 
points, it could be that NUPR1-depleted cells have a possible defect in the elF2 $\alpha$ dephosphorylation process.

Sustained $p$-elF2 $\alpha$ and low levels of GADD34 should affect translational recovery after stress induction. Therefore, to examine the restoration of protein translation in the absence of NUPR1, we induced the UPR for one hour with TPS $(1 \mu \mathrm{M})$ in $N U P R 1^{+/+}$and NUPR1 ${ }^{-/-}$PANC1 clones and assessed the nascent proteins for up to $16 \mathrm{~h}$ later using in situ click chemistry (Figure 7). To do this, cells were incubated with a puromycin analogue bearing a propargyl group for 1 hour, allowing co-translational incorporation at the C-terminus of nascent polypeptides chains. The incorporated propargyl-puromycin form an in situ covalent conjugate by copper catalyzed click reaction with a fluorescently labelled azide (FITC-azide). The reaction enables subsequent analysis of protein synthesis based on FITC fluorescence levels using confocal microscopy and cytometry [30].

NUPR1-depleted cells showed a slower translational recover after stress treatment as shown by a reduction in de novo protein synthesis at 3 and 16 hours At three hours after TPS incubation withdrawal, NUPR $1^{-/}$cells displayed lower levels of fluorescence compared to untreated cells (Figure 7A-C and quantification D), suggesting reduced protein translation. Decreased fluorescence was confirmed by two-way ANOVA, which showed an effect of both TPS $(p<0.0001)$ and NUPR1 $(p<0.0001)$, as well as an interaction between the two factors $(p=0.001)$. Six hours post-TPS treatment, NUPR $1^{+/+}$PANC-1 cells showed increased fluorescence, which is proportional to increased nascent protein synthesis. In line with sustained elF2 $\alpha$ phosphorylation, both $N U P R 1^{-/}$clones maintained lower levels of fluorescence (Figure 7D) until $16 \mathrm{~h}$ post pharmacological stress termination. Confocal results were confirmed at 6 hours of TPS treatment by flow cytometry (Figure 7E).

Thus, our observations suggest a novel role for NUPR1 in modulating protein synthesis in response to cellular stress.

\section{Discussion}

NUPR1 is rapidly activated in response to a variety of stresses including several ER stress inductors such as serum starvation, cycloheximide, ceramide, staurosporine and $\mathrm{CCl}_{4}$ $[2,4,6,19,31]$. Until now, a direct role for NUPR1's within the UPR has not been identified. In this study, we identified a completely novel function for NUPR1 in directly interacting with elF2 $\alpha / p$-elF2 $\alpha$ and affecting the translational machinery regulating ER stress. NUPR1deficient cells showed reduced protein translation following induction of stress both in vivo and in vitro. This was combined with a lack of ER dilation, which is typically associated with re- 
activation of general protein translation, suggested NUPR1 is required for restoring protein translation. Using global (mass spectrometry) and targeted (co-IP, PLA) assays, we showed a novel and direct interaction between NUPR 1 and elF2 $\alpha$, and show this interaction occurs in perinuclear regions of the cell. These findings constitute the first evidence of a direct, nonnuclear role for NUPR1 and are consistent with specific deficits observed in the absence of NUPR1, including reduced protein translation and ultrastructural differences in response to induction of the UPR.

The UPR is a critical intracellular signaling pathway maintaining cellular homeostasis by finely tuning responses to various metabolic, oxidative or inflammatory stresses [31]. A maladaptive UPR has been implicated in a variety of metabolic, neurodegenerative, and inflammatory diseases, as well as cancer. The main goal of an acute activation of UPR is to restore the ER homeostasis [12,32] and promote mechanisms directed to reducing misfolded proteins in the ER. These mechanisms include ubiquitination followed by proteasome degradation of misfolded proteins [33,34], autophagy [16,35], and the transitory arrest of protein synthesis and RNA processing that prevents accumulation of misfolded neo-proteins into the ER $[16,36]$. Efficient activation of these mechanisms allows the cell to survive. Conversely, when these mechanisms are inadequate or sustained, ER-stressed cells initiate programmed cell death [16]. Using several complementary approaches, we have demonstrated NUPR1 affects translation during ER stress, at least in part, by associating with p-elF2 $\alpha / \mathrm{elF} 2 \alpha$ and potentially promoting dephosphorylation of $p$-elF $2 \alpha$, thereby allowing restoration of normal protein synthesis. As a consequence, in NUPR1-deficient cells, protein synthesis is almost completely arrested correlating to prolonged phosphorylation of elF2 $\alpha$. Decreased elF2 $\alpha$ activity, would result in a reduced ER stress response. While we have not shown that NUPR1 interaction affects phosphorylation status of elF $2 \alpha$, the absence of NUPR1 leads to maintained p-eIF2 $\alpha$ and reduced protein translation, consistent with such a function.

It is likely that NUPR1's interaction with -elF2 $\alpha$ is not the only role it plays in the UPR and protein translation. The range of NUPR1 interacting partners identified by MS analysis suggests its potential in regulating numerous functions during cell stress, including several transcriptional regulators, one of such functions could be indeed the transcriptional regulation. We chose to focus on elF $2 \alpha$ as it is a critical translational regulator that mediates the ISR. Upon ER-stress induction, the first cellular event in the UPR cascade involves elF2 $\alpha$ phosphorylation that prompts a protein synthesis shut off to re-establish the pre-stress proteostasis. Both the phosphorylation of elF2 $\alpha$ and the subsequent recovery of protein translation are important stages in a complete UPR. In NUPR1 deficient cells we observed an elevated and prolonged phosphorylation of elF2 $\alpha$ associated with a reduced and delayed 
induction of UPR downstream effectors CHOP, ATF4 and GADD34. The reduced expression and function of ATF4 (a direct regulator of Chop and Gadd34 transcription) is somewhat surprising as Atf4 generally escapes the translation block normally bestowed by p-elF2a. However, it is likely that NUPR1 deficiency affects multiple factors within the UPR, possibly through transcriptional mechanisms. Indeed, we observed deficits in IRE1 signaling suggesting a more widespread effect of NUPR1 deficiency on the UPR. Another possible mechanism involves GADD34. In the later stages of the ER-stress response GADD34 promotes the dephosphorylation of elF $2 \alpha$ thereby creating a negative feedback loop to release the transient protein synthesis block. Loss of GADD34 has been previously associated with a prolonged interruption in protein synthesis [32] and decreased expression of UPR downstream regulators. Since we show specific decreases in GADD34 expression both in vitro and in vivo, it is possible that this decrease contributes to maintained p-elF2 $\alpha$ levels as well. However, our MS data did not demonstrate a direct interaction of NUPR1 with GADD34. Noteworthy, in light of our findings it could also be speculated that the prolonged phosphorylation of elF2 $\alpha$ in absence of NUPR1 is due to an improper elF2 $\alpha$ dephosphorylation. The proposed observation fits with the model that the elF2 $\alpha$ phosphorylation leads to a reduced expression of CHOP in absence of NUPR1. Moreover, we identify a direct interaction between NUPR1 and elF2 $\alpha$ supported by our MS, biochemical and PLA indicate that NUPR1 in addition to transcriptional regulation of $\mathrm{CHOP}$ and GADD34, could potentially contribute to the regulation of elF2 $\alpha$ phosphorylation through direct interaction with proteins involved in elF2 $\alpha$ phosphorylation or dephosphorylation. However, the exact mechanism clearly warrants further investigation. While our data demonstrates NUPR1 functions influence protein translation through interacting with factors involved in translation initiation and regulation, it is likely that NUPR1 affects the UPR through multiple mechanisms.

In conclusion our findings demonstrate a novel role for NUPR1 during ER stress where it participates in the regulation of the UPR and more broadly the integrated stress response by participating in the transcriptional and translational regulation by interacting with elF2 $\alpha$ (Figure 8). Thus, collectively, our data supports an essential role of NUPR1 during ER stress. 


\section{Materials and methods}

\section{Study approval}

All experimental protocols were carried out in accordance with the nationally approved guidelines for the treatment of laboratory animals. All experimental procedures on animals were approved by the Comité d'éthique de Marseille numéro 14 (C2EA-14) in accordance with the European Union regulations for animal experiments.

\section{Mouse strains and Tissue collection.}

For all the in vivo experiments we used $\mathrm{Nupr}^{-/}$mice bear a homozygous deletion of exon 2 [33]. Mice were used between the 5 and 16 weeks of age and as control we used their mating littermates. Animals were kept in the Experimental Animal House of the Centre de Cancérologie de Marseille (CRCM) of Luminy. After sacrifice by cervical dislocation, pieces of pancreas were collected and frozen in cold isopentane for further analysis or directly homogenized in $4 \mathrm{M}$ guanidium isothiocyanate lysis buffer for efficient pancreatic RNA extraction according with Chirgwin et al's procedure [34].

\section{Tunicamycin injections}

Mouse of 5-8 weeks of age were injected intraperitoneally (IP) with $1 \mu \mathrm{g} / \mathrm{g}$ of Tunicamycin (Sigma) using $150 \mathrm{mM}$ of D-Glucose as vehicle. After the reported time point (up to $36 \mathrm{~h}$ ) mice were sacrificed and organs collected.

\section{Cell culture}

MiaPaCa-2 and PANC-1 cells were purchased from ATCC and cultures in DMEM medium (Dulbecco's modified Eagle's medium, Gibco, Life Technologies, Carlsbad, CA, USA), supplemented with $10 \%$ fetal bovine serum (Lonza, Basel, Switzerland) and cultured at $37^{\circ} \mathrm{C}$ and $5 \% \mathrm{CO}_{2}$. Cells were used in all experiments below 20 passages.

\section{Preparation or protein lysates and Western Blotting}

Forty $\mathrm{mg}$ of frozen tissue were cut on dry ice and homogenized with Precellys ${ }^{\circledR}$ (Bertin instruments) in $300 \mu \mathrm{L}$ of ice-cold RIPA buffer (10 mM Tris-Cl (pH 8.0), 1 mM EDTA, $0.5 \mathrm{mM}$ EDTA, $1 \%$ Triton $\mathrm{X}-100,0.1 \%$ sodium deoxycholate, $0.1 \%$ SDS, $140 \mathrm{mM} \mathrm{NaCl}$ ), 
complemented with $0.5 \mu \mathrm{g} / \mathrm{g}$ of protease inhibitor kit (Sigma), $200 \mu \mathrm{M}$ of $\mathrm{Na}_{3} \mathrm{VO}_{4}, 1 \mathrm{mM}$ of PMSF and $40 \mathrm{mM}$ of $\beta$-glycerophosphate. After homogenization, the supernatant was cleared by centrifugation for $30 \mathrm{~min}$ at $14.000 \mathrm{rpm}$ at $4^{\circ} \mathrm{C}$. Protein lysate content was quantified by micro BCA assay (Thermo-Fisher Scientific) and $40 \mu \mathrm{g}$ of protein were resolved by SDSPAGE, transferred to nitrocellulose membrane for 1 or 2 hours. Membranes were next blocked with TBS (tris-buffered saline) in 5\% BSA and blotted overnight with primary antibody (1:500 dilution in TBS 5\% BSA). After washes, the membrane was incubated with HPR-conjugated secondary antibody (Boster, Pleasanton CA, USA) for 1 hour at room temperature (1:5000 dilution in TBS-5\% BSA). Subsequently, the membrane was washed and revealed with ECL (enhanced chemo-luminescence). Chemiluminescent signal was detected in a G-Box (Syngene). The following antibodies were used: rabbit monoclonal ATF4 (D4B8), mouse monoclonal CHOP (L63F7), rabbit monoclonal XBP1s (E9V3E), rabbit monoclonal, BiP (C50B12), rabbit monoclonal elF2 $\alpha X^{\circledR}{ }^{\circledR}$ (D7D3), rabbit monoclonal Phospho-elF2 $\alpha X^{\circledR}{ }^{\circledR}$ (Ser51) (D9G8), and rabbit monoclonal Phospho-PERK (Thr980) were from Cell Signaling Technology; (G.305.4), rabbit polyclonal antibody Phospho-IRE1 alpha (Ser724) (PA1-16927) is from Thermo Fisher; and mouse monoclonal $\beta$-actin (\#A5316) is from Sigma. Quantification of signal was performed using ImageJ software. Mean band intensity plotted over the intensity of elF2 $\alpha \pm$ SEM $(n=3)$ and unpaired Student's $t$-test was used for statistical analysis.

\section{Preparation of RNA and RT-qPCR}

RNA from murine pancreata was extracted after $16 \mathrm{~h}$ of intraperitoneal injections of Tunicamycin following the Chirgwin procedure [34]. Total RNA from cells was obtained using RNAeasy kit (Quiagen) following manufacturer's instruction. The RNA integrity was assessed with Agilent 2100 Bioanalyzer with the RNA 6000 Nano chip Kit. The RNAs were reversetranscribed using GO Script kit (Promega) following manufacturer's instruction. RT-qPCR were performed using Aria mix using Promega reagents. Primer sequences are described in Supplementary Table 4. mRNAs were quantified relative to Rp/O. Data are presented in the graphs as Log Fold Change compared to $\mathrm{Nupr}^{+/+}$controls (mice IP injected with vehicle, 150 $\mathrm{mM}$ D-Glucose) levels of expression. Significant differences were calculated using two-way ANOVA with post hoc Sidak test $(n=6)$.

\section{Transmission Electron Microscopy}

Mice were perfused with $4 \%$ cold PFA and $2.5 \%$ glutaraldehyde. Pancreatic tissue was then immersed overnight in $0.1 \mathrm{M}$ Soresen buffer, post-fixed in $1 \%$ osmium tetroxide, and in bloc 
stained with $3 \%$ uranyl acetate. The tissue was dehydrated with increasing concentrations of ethanol on ice and acetone before being embedded in Epon. Ultrathin sections $(70 \mathrm{~nm})$ were prepared using a Leica UCT Ultramicrotome (Leica, Austria) and stained with uranyl acetate and lead citrate and deposited on formvar-coated slot grids. The grids were observed in an FEI Tecnai G2 at $200 \mathrm{KeV}$ and acquisition was performed on a Veleta camera (Olympus, Japan).

\section{NUPR1 expression vector transfection}

MiaPaCa-2 cells were seeded in 12-well plates and transfected with $3 \mu \mathrm{g}$ of DNA (NUPR1GFP, NUPR1-Flag or control vector) and $3 \mu \mathrm{L}$ of Lipofectamine 3000 Transfection Reagent (Thermo Fisher Scientific) per well. Cells were assayed after $24 \mathrm{~h}$ post-transfection.

\section{Co-Immunoprecipitation}

MiaPaCa-2 cells, expressing GFP-NUPR1, were plated in $10 \mathrm{~cm}^{2}$ dishes. When reached $80 \%$ confluence were treated with either $1 \mu \mathrm{M}$ of Thapsigargin or glucose starved for $24 \mathrm{~h}$. After that time cells were lysed on ice by using HEPES based lysis buffer containing proteases inhibitor cocktail (1:200) (Sigma P8340). Lysates were cleared for $10 \mathrm{~min}$ at $14000 \mathrm{rpm}$ at $4^{\circ} \mathrm{C}$ and protein concentration of the supernatant was determined by using Protein Assay (BioRad). The co-immunoprecipitation was performed using GFP trap ${ }^{\circledR}$ beads (Chromotek) following manufacturer's protocol or rabbit monoclonal antibody specific for elF2 $\alpha \mathrm{XP}^{\circledR}$ (D7D3). Immunoprecipitates were pelleted, washed with lysis buffer three times, and then PBS. The resultant proteins were denatured and blotted against elF2 $\alpha$, p-elF $2 \alpha$ and anti GFP. To perform the reverse co-IP, MiaPaCa-2 cells expressing Flag-NUPR1 or Flag-GFP were grown to $70 \%$ confluence and treated as described above. Cells were lysed on ice using HEPES based lysis buffer containing $10 \mathrm{mM}$ NEM (N-Ethylmaleimide, Sigma 04259) and a proteases inhibitor cocktail (1:200; Sigma P8340). Lysates were centrifuged for 10 min at 14, $000 \mathrm{rpm}$ at $4^{\circ} \mathrm{C}$. Protein concentration of the supernatant was determined using Protein Assay (Bio-Rad), and equal amounts of protein incubated with $30 \mu \mathrm{l}$ of anti-Flag M2 coated beads under rotation for $2 \mathrm{~h}$ at $4^{\circ} \mathrm{C}$. Beads were then washed three times with cold lysis buffer and proteins were eluted using $250 \mu \mathrm{l}$ ammonium hydrogen carbonate buffer containing $0.1 \mu \mathrm{g} / \mu \mathrm{l}$ of Flag peptide for $90 \mathrm{~min}$ at $4^{\circ} \mathrm{C}$ while rotating. After a short spin, the supernatant was recovered by using a Hamilton syringe. Eluted proteins were collected and analyzed by mass spectrometry. 


\section{Click chemistry and fluorescence detection}

PANC-1 and modified PANC-1 cells were grown on glass coverslips in DMEM supplemented with $10 \%$ bovine calf serum. Cell were treated with $1 \mu \mathrm{M}$ Thapsigargin (TPS) for $1 \mathrm{~h}$ then incubated in fresh media without TPS. After 3, 6 or 16 hours, O-propargyl puromycin (OPpuro) was added to cells in complete culture medium for $1 \mathrm{~h}$. Cells were then washed with PBS and fixed with $4 \%$ PFA in PBS. After fixation cells were permeabilized with $0.3 \%$ Triton-X in PBS. Following removal of detergent by PBS washes, CuAAC detection of OP-puro incorporated into nascent protein was performed by reacting the fixed cells for $1 \mathrm{~h}$ at room temperature with $20 \mu \mathrm{M}$ FITC azide, as previously described [35]. After the click chemistry reaction, coverslips were washed several times with TBST, counterstained with Hoechst, and mounted in standard mounting media. The stained cells were imaged by LSM 510 META confocal microscope (Zeiss) and on a Nikon Eclipse 90i fluorescence microscope. Stained cells were also quantified by Flow-cytometry in a MACSQuant-VYB (Miltenyi Biotec, Surrey, UK). Data analysis was carried out by using the FlowJo software. The intensity of the fluorescent OP-puro stain in single cells was quantified by imageJ. Statistical significance was calculated by using two-way ANOVA and corrected for Sidak s test.

\section{Proximity ligation assay}

MiaPaCa-2 transfected with Flag-NUPR1 were treated with TPS $(1 \mu \mathrm{M})$, or glucose starved. After the indicated time points cells were washed twice in PBS, fixed, washed twice again, permeabilized in PBS/0.1\% Triton X-100, and saturated with blocking solution for 30 min before immune-staining with Duolink by using PLA Technology (Sigma-Aldrich) following the manufacturer's protocol. Slides were processed for in situ PLA by using sequentially the Duolink in situ Detection Reagents Green, Duolink In Situ PLA Probe Anti-Mouse MINUS, and Duolink In Situ PLA Probe Anti-Rabbit PLUS. The following antibodies were used: rabbit monoclonal elF2 $\alpha-X P^{\circledR}$ (D7D3, from Cell Signaling Technology), rabbit monoclonal PhosphoelF2 $\alpha X^{\circledR}$ (Ser51) (D9G8, from Cell Signaling Technology), mouse monoclonal antibody antiFLAG M2 (from Sigma-Aldrich). In these experiments, green fluorescence corresponds to the PLA-positive signal, and it indicates that the two molecules belong to the same protein complex. Blue fluorescence corresponds to nuclei (so-called DAPI staining). Protein overexpression was used to obtain a clearer and better signal. Preparations were mounted using Prolong Gold antifade reagent (Invitrogen) and image acquisition was carried out on an LSM 510 META confocal microscope (Zeiss) and on a Nikon Eclipse 90i fluorescence microscope. 


\section{Mass Spectrometry Analysis}

Protein extracts were loaded on NuPAGE 4-12\% Bis-Tris acrylamide gels according to the manufacturer's instructions (Invitrogen). Running was stopped as soon as proteins stacked in a single band. Protein-containing bands were stained with Imperial Blue (Pierce), cut from the gel, and digested with high-sequencing-grade trypsin (Promega, Madison, WI) before mass spectrometry analysis according to Shevchenko et al. (44). Mass spectrometry analysis was carried out by LC-MS/MS using an LTQ-Velos-Orbitrap or a $Q$ Exactive Plus Hybrid Quadrupole-Orbitrap (Thermo Electron, Bremen, Germany) coupled online with a nanoLC Ultimate3000RSLC chromatography system (Dionex, Sunnyvale, CA). Five microliters corresponding to $1 / 5$ of the whole sample were injected in triplicate on the system. After sample preconcentration and washing on a Dionex Acclaim PepMap $100 \mathrm{C} 18$ column $(2 \mathrm{~cm}$ x $100 \mu \mathrm{m}$ i.d. $100 \AA, 5 \mu \mathrm{m}$ particle size), peptides were separated on a Dionex Acclaim PepMap RSLC C18 column ( $15 \mathrm{~cm} \times 75 \mu \mathrm{m}$ i.d., $100 \AA, 2 \mu \mathrm{m}$ particle size) at a flow rate of $300 \mathrm{~nL} / \mathrm{min}$, a two-step linear gradient $(4-20 \%$ acetonitrile/H2O; $0.1 \%$ formic acid for $90 \mathrm{~min}$ and $20-45 \%$ acetonitrile/ $\mathrm{H} 2 \mathrm{O} ; 0.1 \%$ formic acid for $30 \mathrm{~min}$ ). For peptides ionization in the nanospray source, voltage was set at $1.9 \mathrm{kV}$ and the capillary temperature at $275^{\circ} \mathrm{C}$. All samples were measured in a data-dependent acquisition mode. Each experiment was preceded by a blank run to monitor system background. The peptide masses were measured in the LTQ-velos-orbitrap in a survey full scan (scan range 300-1700 m/z, with $30 \mathrm{~K} \mathrm{FWHM}$ resolution at $\mathrm{m} / \mathrm{z}=400$, target $A G C$ value of $1.00 \times 106$, and maximum injection time of 200 $\mathrm{ms})$. In parallel to the high-resolution full scan in the Orbitrap, the data dependent CID scans of the 10 most intense precursor ions were fragmented and measured in the linear ion trap (normalized collision energy of $35 \%$, activation time of $10 \mathrm{~ms}$, target AGC value of $1 \times 104$, maximum injection time $100 \mathrm{~ms}$, and isolation window $2 \mathrm{Da}$ ). Parent masses obtained in Orbitrap analyzer were automatically calibrated on 445.1200 locked mass. Dynamic exclusion was implemented with a repeat count of 1 and exclusion time of $30 \mathrm{~s}$.

In the $Q$ Exactive Plus Hybrid Quadrupole-Orbitrap, the peptide masses were measured in a survey full scan (scan range $375-1500 \mathrm{~m} / \mathrm{z}$, with $70 \mathrm{~K}$ FWHM resolution at $\mathrm{m} / \mathrm{z}=400$, target $A G C$ value of $3.00 \times 106$ and maximum injection time of $100 \mathrm{~ms}$ ). Following the high-resolution full scan in the Orbitrap, the 10 most intense data-dependent precursor ions were successively fragmented in higher energy collisional dissociation (HCD) cell and measured in Orbitrap (normalized collision energy of $25 \%$, activation time of $10 \mathrm{~ms}$, target AGC value of $1.00 \times 103$, intensity threshold $1.00 \times 104$ maximum injection time $100 \mathrm{~ms}$, isolation window $2 \mathrm{~m} / \mathrm{z}, 17.5 \mathrm{~K}$ FWHM resolution, scan range 200 to $2000 \mathrm{~m} / \mathrm{z}$ ). Dynamic exclusion was implemented with a repeat count of 1 and exclusion time of $20 \mathrm{~s}$. 


\section{Mass Spectrometry Data Analysis}

Raw files generated from mass spectrometry analysis were processed using Proteome Discoverer 1.4.1.14 (Thermo Fisher Scientific). This software was used to search data via inhouse Mascot server (version 2.3.0; Matrix Science, London, U.K.) against the Human database subset of the SwissProt database (version 2017.03, 20184 human entries). A database search was done by using the following settings: a maximum of two trypsin miscleavage allowed, methionine oxidation and protein $\mathrm{N}$-acetylation as dynamic modifications, and cysteine carbamido-methylation as fixed modification. A peptide mass tolerance of $6 \mathrm{ppm}$ and a fragment mass tolerance of $0.8 \mathrm{Da}$ were allowed for search analysis. Only peptide identified with a FDR $<1 \%$ were used for protein identification.

To calculate the confident score (from 0 to 100\%) for NUPR1-interacting proteins identified by MS, we used a formula derived from Bonacci et al. [36] based on peptide number count: $\mathrm{K}=$ total peptide number in control IP; $\mathrm{V}=$ total peptide number in NUPR1 IP; Conf = $\left((2 \mathrm{~V})^{2} /\left(1+(2 \mathrm{~V})+(2 \mathrm{~K})^{2}\right)^{*} 100-100 /(1+(2(\mathrm{~V}-\mathrm{K})) ;=0\right.$ if < 0 ; Values above 50 are usually considered to be confident. 


\section{Acknowledgements}

The work was supported by La ligue Contre le Cancer, INCa, Canceropole PACA and INSERM. The electron microscopy experiments were performed in the PiCSL-FBI core facility (IBDM, AMU-Marseille). 


\section{References}

1 Mallo GV, Fiedler F, Calvo EL, Ortiz EM, Vasseur S, Keim V, Morisset J \& lovanna JL (1997) Cloning and expression of the rat $\mathrm{p} 8 \mathrm{cDNA}$, a new gene activated in pancreas during the acute phase of pancreatitis, pancreatic development, and regeneration, and which promotes cellular growth. J Biol Chem 272, 32360-32369.

2 Grasso D, Garcia MN, Hamidi T, Cano C, Calvo E, Lomberk G, Urrutia R \& lovanna JL (2014) Genetic inactivation of the pancreatitis-inducible gene Nupr1 impairs PanIN formation by modulating Kras G12D-induced senescence. Cell Death Differ 21, 1633.

3 Emma MR, lovanna JL, Bachvarov D, Puleio R, Loria GR, Augello G, Candido S, Libra M, Gulino A \& Cancila V (2016) NUPR1, a new target in liver cancer: implication in controlling cell growth, migration, invasion and sorafenib resistance. Cell Death Dis 7, e2269.

4 Giroux V, Malicet C, Barthet M, Gironella M, Archange C, Dagorn J-C, Vasseur S \& lovanna $\mathrm{JL}$ (2006) p8 is a new target of gemcitabine in pancreatic cancer cells. Clin cancer Res 12, 235-241.

5 Hamidi T, Cano CE, Grasso D, Garcia MN, Sandi MJ, Calvo EL, Dagorn J-C, Lomberk G, Urrutia R, Goruppi S, Carracedo A, Velasco G \& lovanna JL (2012) Nupr1-Aurora Kinase A Pathway Provides Protection against Metabolic Stress-Mediated AutophagicAssociated Cell Death. Clin Cancer Res 18, 5234 LP - 5246.

6 Averous J, Lambert-Langlais S, Cherasse Y, Carraro V, Parry L, B'chir W, Jousse C, Maurin AC, Bruhat A \& Fafournoux P (2011) Amino acid deprivation regulates the stressinducible gene p8 via the GCN2/ATF4 pathway. Biochem Biophys Res Commun 413, 24-29.

7 Garcia-Montero A, Vasseur S, Mallo GV, Soubeyran P, Dagorn JC \& lovanna JL (2001) Expression of the stress-induced p $8 \mathrm{mRNA}$ is transiently activated after culture medium change. Eur J Cell Biol 80.

8 Barbosa-Sampaio HC, Liu B, Drynda R, De Ledesma AMR, King AJ, Bowe JE, Malicet C, lovanna JL, Jones PM \& Persaud SJ (2013) Nupr1 deletion protects against glucose intolerance by increasing beta cell mass. Diabetologia 56, 2477-2486.

9 Clark DW, Mitra A, Fillmore RA, Jiang WG, Samant RS, Fodstad O \& Shevde LA (2008) NUPR1 interacts with $\mathrm{p} 53$, transcriptionally regulates $\mathrm{p} 21$ and rescues breast epithelial cells from doxorubicin-induced genotoxic stress. Curr Cancer Drug Targets 8, 421-430.

10 Hamidi T, Cano CE, Grasso D, Garcia MN, Sandi MJ, Calvo EL, Dagorn J-C, Lomberk G, Goruppi S, Urrutia R, Carracedo A, Velasco G \& lovanna JL (2013) NUPR1 works against the metabolic stress-induced autophagy-associated cell death in pancreatic cancer cells. Autophagy 9, 95-97.

11 Taïeb D, Malicet C, Garcia S, Rocchi P, Arnaud C, Dagorn J, lovanna JL \& Vasseur S (2005) Inactivation of stress protein p8 increases murine carbon tetrachloride 
hepatotoxicity via preserved CYP2E1 activity. Hepatology 42, 176-182.

12 Schönthal $\mathrm{AH}$ (2012) Endoplasmic reticulum stress: its role in disease and novel prospects for therapy. Scientifica (Cairo) 2012, 857516.

13 Kubisch CH \& Logsdon CD (2008) Endoplasmic reticulum stress and the pancreatic acinar cell. Expert Rev Gastroenterol Hepatol 2, 249-260.

14 Ron D \& Walter P (2007) Signal integration in the endoplasmic reticulum unfolded protein response. Nat Rev Mol cell Biol 8, 519.

15 Chambers JE, Dalton LE, Clarke HJ, Malzer E, Dominicus CS, Patel V, Moorhead G, Ron D \& Marciniak SJ (2015) Actin dynamics tune the integrated stress response by regulating eukaryotic initiation factor $2 \alpha$ dephosphorylation. Elife 4, e04872.

16 Livezey M, Huang R, Hergenrother PJ \& Shapiro DJ (2018) Strong and sustained activation of the anticipatory unfolded protein response induces necrotic cell death. Cell Death Differ 25, 1796-1807.

17 Kato H \& Nishitoh H (2015) Stress responses from the endoplasmic reticulum in cancer. Front Oncol 5, 93.

18 Santofimia-Castaño P, Lan W, Bintz J, Gayet O, Carrier A, Lomberk G, Neira JL, González A, Urrutia R, Soubeyran P \& lovanna J (2018) Inactivation of NUPR1 promotes cell death by coupling ER-stress responses with necrosis. Sci Rep 8, 16999.

19 Cai D, Huang E, Luo B, Yang Y, Zhang F, Liu C, Lin Z, Xie W-B \& Wang H (2016) Nupr1/Chop signal axis is involved in mitochondrion-related endothelial cell apoptosis induced by methamphetamine. Cell Death Dis 7, e2161-e2161.

20 Bertolotti A, Zhang Y, Hendershot LM, Harding HP \& Ron D (2000) Dynamic interaction of $\mathrm{BiP}$ and ER stress transducers in the unfolded-protein response. Nat Cell Biol 2, 326.

21 Harding HP, Zhang Y, Zeng H, Novoa I, Lu PD, Calfon M, Sadri N, Yun C, Popko B \& Paules R (2003) An integrated stress response regulates amino acid metabolism and resistance to oxidative stress. Mol Cell 11, 619-633.

22 Marciniak SJ, Yun CY, Oyadomari S, Novoa I, Zhang Y, Jungreis R, Nagata K, Harding HP \& Ron D (2004) CHOP induces death by promoting protein synthesis and oxidation in the stressed endoplasmic reticulum. Genes Dev 18, 3066-3077.

23 Kramer R, Weber TK, Arceci R, Ramchurren N, Kastrinakis W V, Steele Jr G \& Summerhayes IC (1995) Inhibition of N-linked glycosylation of P-glycoprotein by tunicamycin results in a reduced multidrug resistance phenotype. Br J Cancer 71, 670.

24 Reid DW, Chen Q, Tay AS-L, Shenolikar S \& Nicchitta C V (2014) The unfolded protein response triggers selective mRNA release from the endoplasmic reticulum. Cell 158, 1362-1374.

25 Sicari D, Delaunay-Moisan A, Combettes L, Chevet E \& Igbaria A (2019) A guide to assessing endoplasmic reticulum homeostasis and stress in mammalian systems. FEBS 
$J$.

26 Schuck S, Prinz WA, Thorn KS, Voss C \& Walter P (2009) Membrane expansion alleviates endoplasmic reticulum stress independently of the unfolded protein response. J Cell Biol $187,525-536$.

27 Kubisch CH \& Logsdon CD (2007) Secretagogues differentially activate endoplasmic reticulum stress responses in pancreatic acinar cells. Am J Physiol Liver Physiol 292, G1804-G1812.

28 Mayerle J, Sendler M \& Lerch MM (2013) Secretagogue (Caerulein) induced pancreatitis in rodents. Pancreapedia Exocrine Pancreas Knowl Base.

29 Santofimia-Castaño P, Xia Y, Lan W, Zhou Z, Huang C, Peng L, Soubeyran P, VelázquezCampoy A, Abián O, Rizzuti B, Neira JL \& lovanna J (2019) Ligand-based design identifies a potent NUPR1 inhibitor exerting anticancer activity via necroptosis. $J$ Clin Invest 129, 2500-2513.

30 Liu J, Xu Y, Stoleru D \& Salic A (2012) Imaging protein synthesis in cells and tissues with an alkyne analog of puromycin. Proc Natl Acad Sci 109, 413-418.

31 Chowdhury UR, Samant RS, Fodstad O \& Shevde LA (2009) Emerging role of nuclear protein 1 (NUPR1) in cancer biology. Cancer Metastasis Rev 28, 225-232.

32 Kojima E, Takeuchi A, Haneda M, Yagi F, Hasegawa T, Yamaki K, Takeda K, Akira S, Shimokata K \& Isobe K (2003) The function of GADD34 is a recovery from a shutoff of protein synthesis induced by ER stress-elucidation by GADD34-deficient mice. FASEB J 17, 1-18.

33 Vasseur S, Hoffmeister A, Garcia-Montero A, Mallo GV, Feil R, Kühbandner S, Dagorn JC \& lovanna JL (2002) p8-deficient fibroblasts grow more rapidly and are more resistant to adriamycin-induced apoptosis. Oncogene 21, 1685.

34 Chirgwin JM, Przybyla AE, MacDonald RJ \& Rutter WJ (1979) Isolation of biologically active ribonucleic acid from sources enriched in ribonuclease. Biochemistry 18, 52945299.

35 Salic A \& Mitchison TJ (2008) A chemical method for fast and sensitive detection of DNA synthesis in vivo. Proc Natl Acad Sci 105, 2415-2420.

36 Bonacci T, Audebert S, Camoin L, Baudelet E, Bidaut G, Garcia M, Witzel I-I, Perkins ND, Borg J-P \& lovanna J-L (2014) Identification of new mechanisms of cellular response to chemotherapy by tracking changes in post-translational modifications by ubiquitin and ubiquitin-like proteins. J Proteome Res 13, 2478-2494. 


\section{Figure Legends}

Figures were realized with Biorender

\section{Figure 1.}

\section{Biochemical evaluation of ER-stress related proteins after tunicamycin treatment in the}

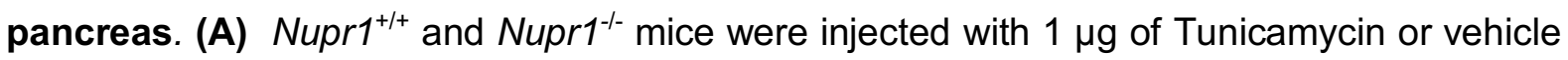
and $16 \mathrm{~h}$ (150 mM of D-glucose) post injection pancreas was extracted and tissue lysed. Image show representative western blots of the PERK branch activation and its quantification (B) using ImageJ software. Mean band intensity plotted \pm SEM; Significant differences were calculated by two-way ANOVA with post hoc Sidak test $(n=3)$. (C) Representative western blotting of $p$-elF2 $\alpha$ of pancreatic lysates from Nupr $1^{+/+}$and $\mathrm{Nupr}^{-/-}$after Tun injections over a period of time (Ctrl, $3 \mathrm{~h}, 8 \mathrm{~h}, 24 \mathrm{~h}$ ); (D) quantification of (C) using ImageJ software. Mean band intensity plotted \pm SEM; Significant differences were calculated by two-way ANOVA with post hoc Sidak test $(n=3)$. (E) Representative western blots of the IRE1 $\alpha$ branch of the UPR of tissue lysates dissected from from Nupr1 ${ }^{+/+}$and $\mathrm{Nupr}^{1^{-/}}$and quantification (F) using ImageJ software. Mean band intensity plotted \pm SEM; Significant differences were calculated by twoway ANOVA with post hoc Sidak test. Statistically significant differences between Nupr1 ${ }^{+/+}$and Nupr1 ${ }^{-1-}$ mice are shown $\left({ }^{*} p<0.02,{ }^{* *} p<0.01,{ }^{* * *} p<0.001,{ }^{* * * *} p<0.0001\right.$ ). (G) RT-qPCR results of mRNA expression of BiP, Atf6, Xbp1d, Atf4 and Chop, Gadd34 and Erdj4 RNA was extracted from $\mathrm{Nupr}^{+/+}$and $\mathrm{Nupr}^{-/-}$mice treated with Tun or Vehicle for 16h. Significant differences were calculated by two-way ANOVA with post hoc Sidak test $(n=6)$. Statistically significant differences are shown $\left({ }^{*} p<0.03,{ }^{* *} p<0.001,{ }^{* * *} p=0.001,{ }^{* * *} p<0.0001\right)$. 

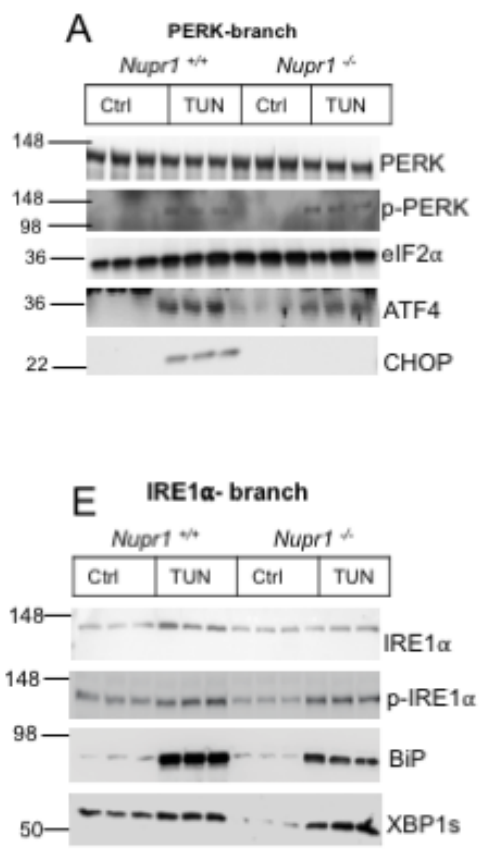

FIGURE 1
B ㅁㅁㅁ

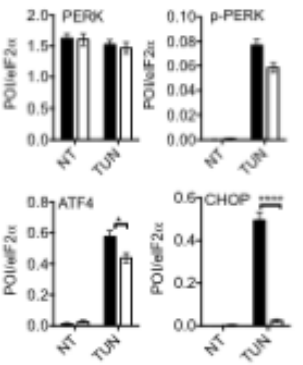

F 믈
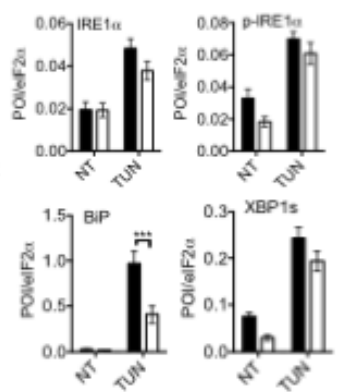

G : Mupre
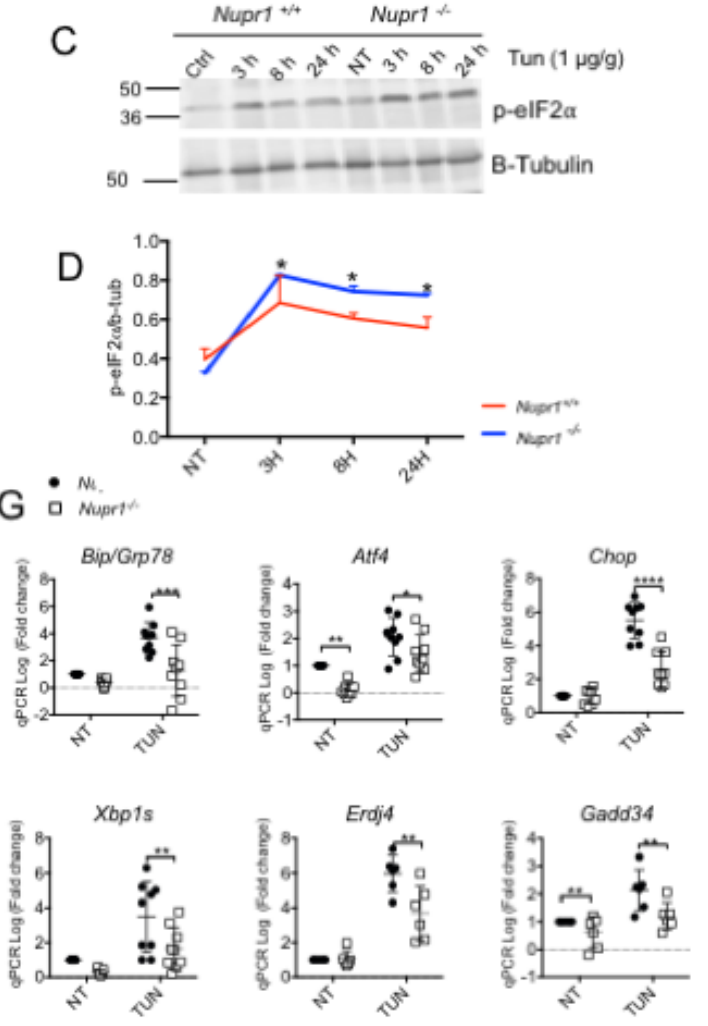


\section{Figure 2.}

Electron micrographs of $\mathrm{Nupr}^{+/+}$and $\mathrm{Nupr}^{-/-}$murine pancreata after ER stress induction with tunicamycin (16 and $36 \mathrm{~h}$ ). Representative transmission electron micrograph images of $\mathrm{Nupr}^{+/+}$and Nupr1\% pancreatic tissue of perfusion fixed mice injected intra peritoneally (IP) with vehicle (NT, A and B and insets) or Tunicamycin (TUN, $1.0 \mu \mathrm{g} / \mathrm{g}$ ), at 16 (C and $\mathbf{D}$ ) or 36 hours (E and $\mathbf{F}$ ) post injection. Arrows point to the ER and asterisks indicate dilated ER cisternae. $\mathbf{N u = n u c l e u s ; ~} \mathbf{z y}=$ zymogen granules.
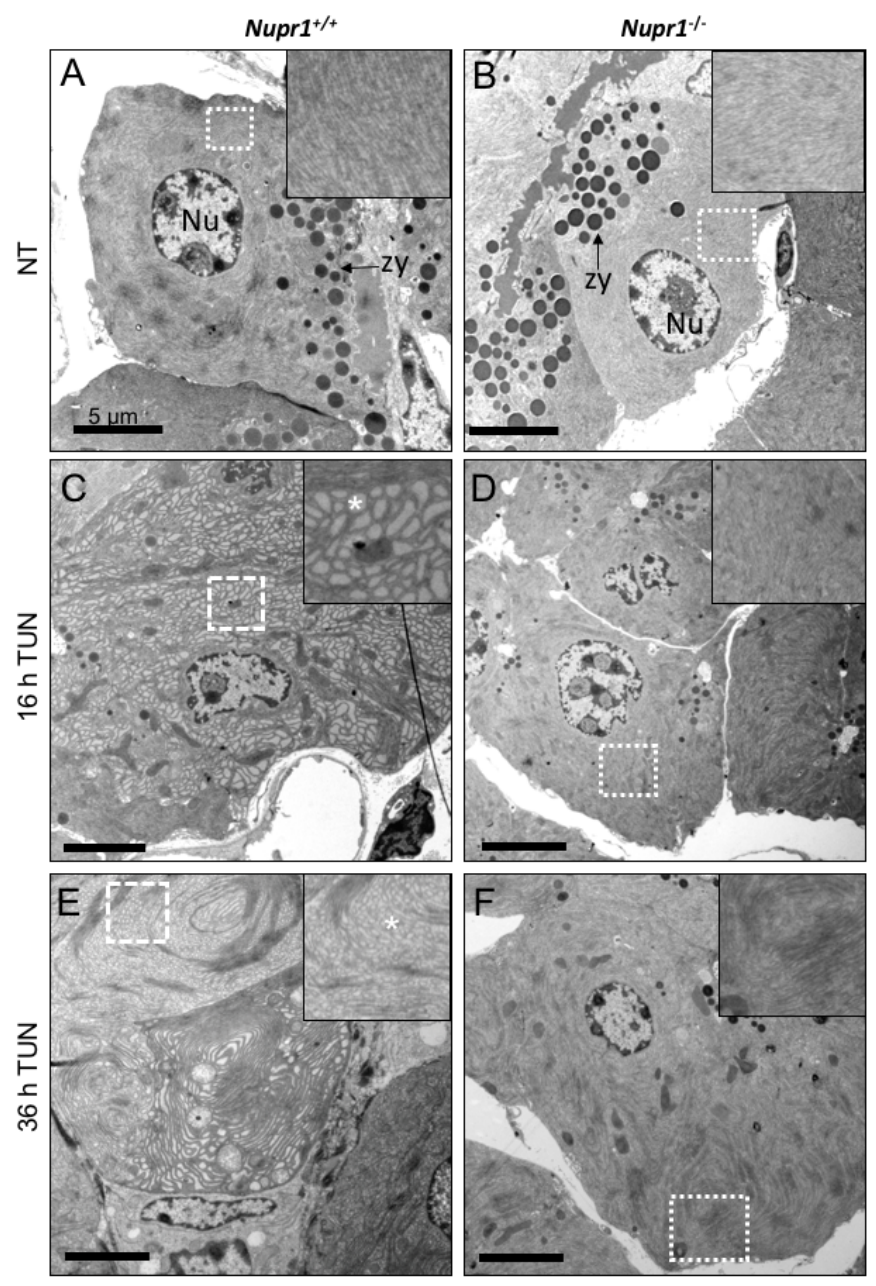

FIGURE 2 


\section{Figure 3.}

Quantification of amylase content and amylase release levels in acinar cells isolated

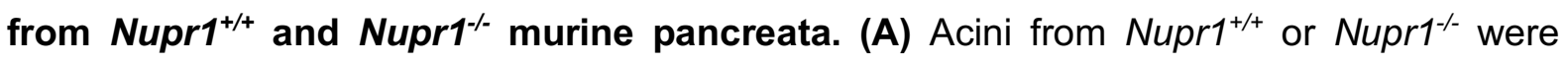
dissociated and treated with increasing concentration of Cerulein. Amylase release onto the media was then measured. (B) Image of isolated acini from Nupr1 $1^{+/+}$or Nupr1/- mice. (C) Quantification of total amylse content in $\mathrm{Nupr}^{+/+}$and $\mathrm{Nupr}^{-/}$expressed in $\mathrm{mU} / \mathrm{mL}$. Total amylase in Nupr1\% acini was significantly lower than from acini of Nupr1. Statistical significance was calculated with unpaired two-tailed $t$-test ${ }^{*} p<0.04, n=4$ ). (D) Amylase release from isolated $\mathrm{Nupr}^{+/+}$or $\mathrm{Nupr}^{-/-}$acinar cells following stimulation with increased amounts of cerulein for $30 \mathrm{~min}$. Nupr ${ }^{+/+}$derived acinar cells released higher percentage of Amylase compared to Nupr1\%. Statistical significance was measured with two-way ANOVA with post hoc Sidak test; ${ }^{*} p<0.01,{ }^{* *} p<0.014,{ }^{* * * *} p<0.0001 ; \mathrm{n}=4$ mice).

\section{A}

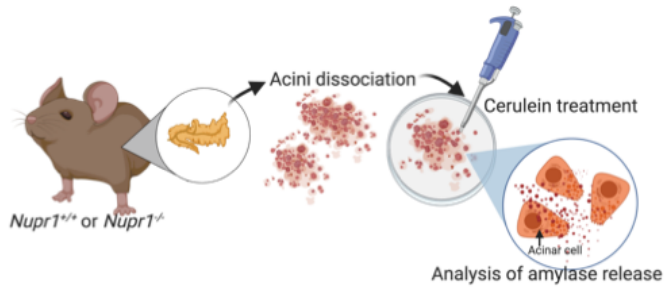

B

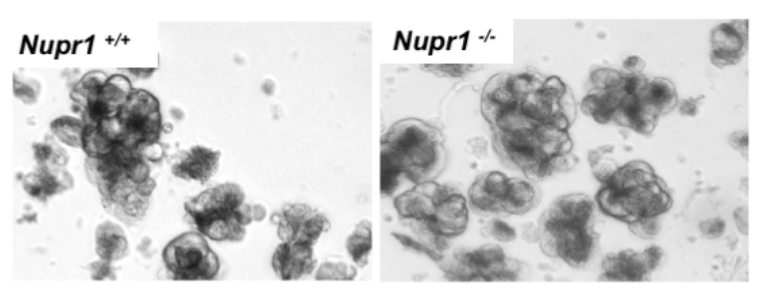

C
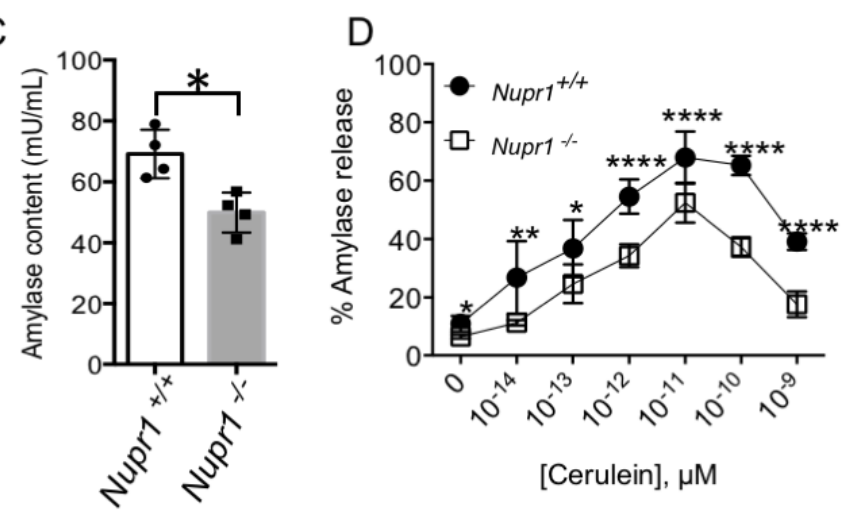

FIGURE 3 


\section{Figure 4.}

Identification of putative NUPR1 interacting proteins. (A) Venn diagram showing putative NUPR1-interacting proteins following glucose starvation or thapsigargin (TPS, $1 \mu \mathrm{M}, 24$ hours) treatment. (B) Quantification of mass spectrometry peak areas of NUPR1-associated eukaryotic initiation factors ( $n=3$, one-way ANOVA, ${ }^{*} p=0.02,{ }^{* *} p=0.002$, ${ }^{* * *} p=0.0002$ ). (C) Extracts from MiaPaCa-2 cells transiently transfected with GFP-NUPR1 were subjected to coimmunoprecipitation with GFP-trap ${ }^{\circledR}$ beads or agarose beads followed by western blotting with the antibodies against $p$-elF $2 \alpha$ and elF $2 \alpha$.Co-Immunoprecipitation assay of GFP-taggedNUPR 1 confirm p-elF2 $\alpha$ and elF2 $\alpha$ interaction. (D) Co-Immunoprecipitation of GFP-taggedNUPR1 with elF2 $\alpha$ demonstrate the reciprocal interaction is effective.

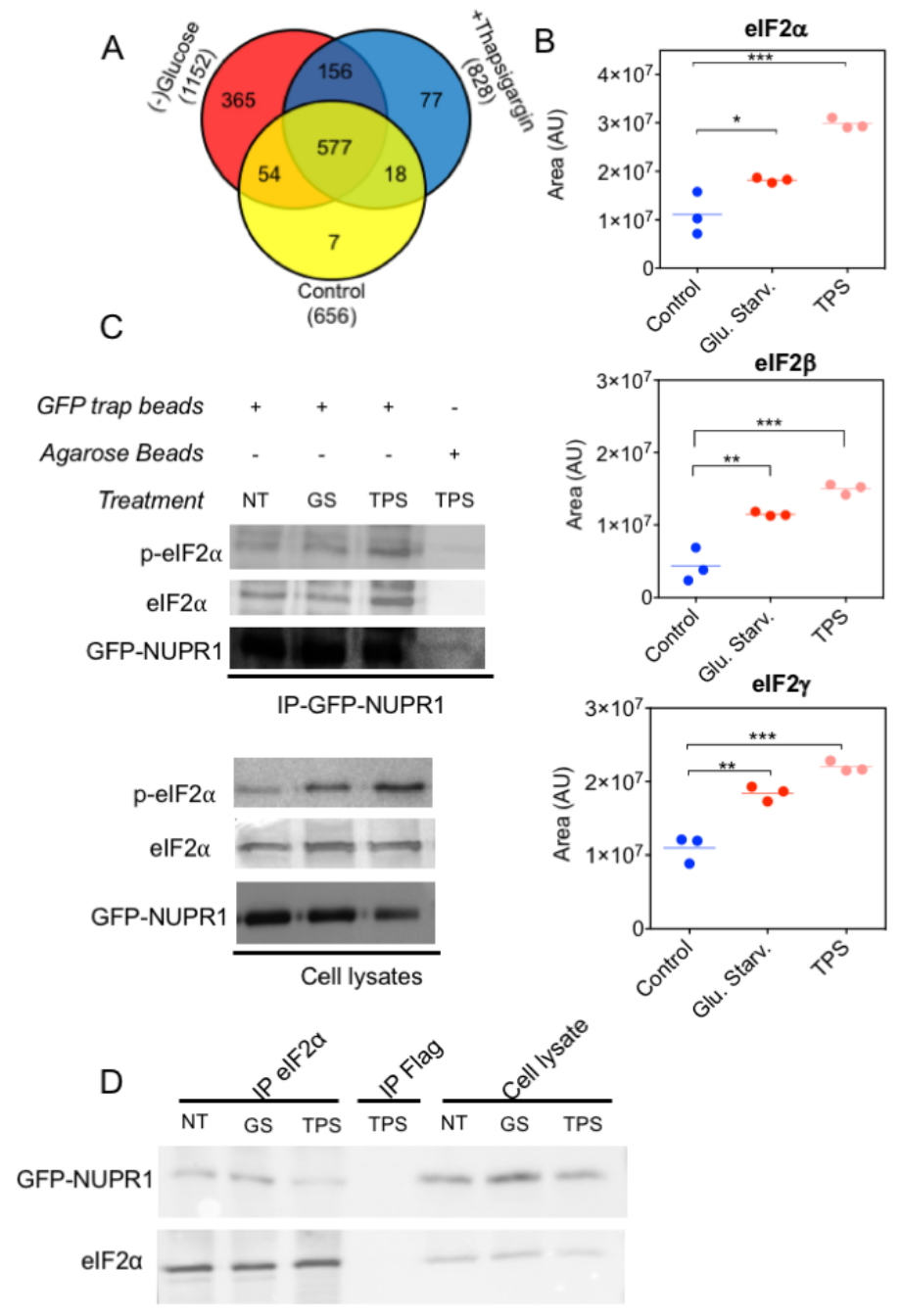

FIGURE 4 


\section{Figure 5.}

\section{In situ proximity ligation assay (PLA) between Flag-NUPR1 and elF2 $\alpha$ / p-elF2 $\alpha$ confirms} the interaction of the proteins. Representative images of PLA experiment for Flag-NUPR1 and elF2 $\alpha(\mathbf{A})$ or Flag-NUPR1 and p-elF2 $\alpha$ (B) were used to reveal interaction in Control MiaPaCa-2 cells or following either thapsigargin treatment (TPS, $1 \mu \mathrm{M}$ ) or glucose-starved (GS) for 24 hours. (B-D) PLA quantification was performed with ImageJ and involved counting the number of green pixels. Data are means of 10 field each containing not less than 150 nuclei. Statistical significance was calculated using ordinary One-way ANOVA values and corrected for multiple comparison's using Dunnet's test ( $\left.{ }^{*} p \leq 0.001\right)$. Magnification $60 \times$.

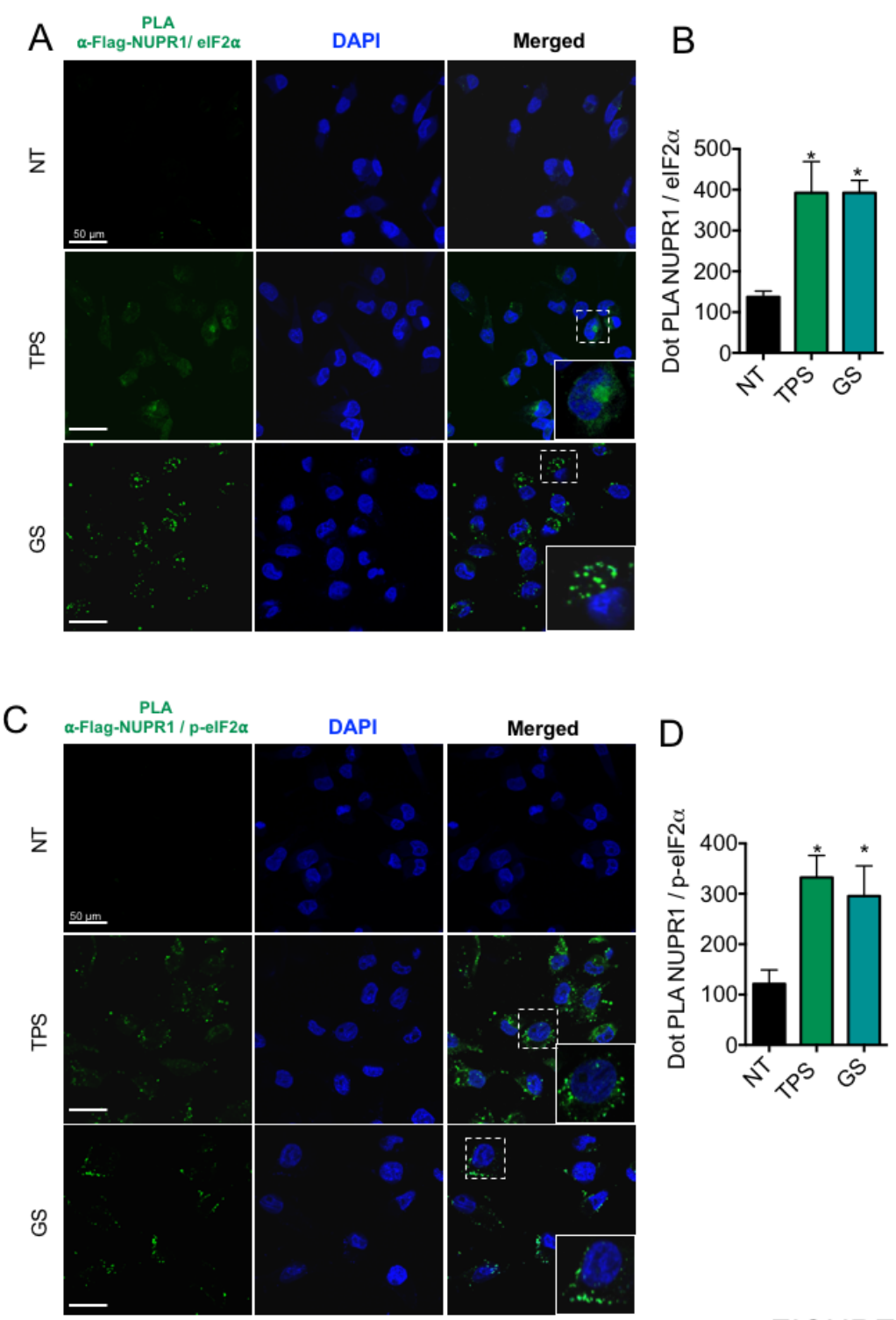

FIGURE 5 


\section{Figure 6.}

EIF2 $\alpha$ phosphorylation in NUPR1-deficient and matched control PANC-1 cells in response to thapsigargin (TPS) induced ER-stress. (A) Analysis of p-elF2 $\alpha$ expression following 6, 12 and $24 \mathrm{~h}$ TPS treatment in protein extracts of PANC-1 cells with NUPR1 $1^{+/+}$ (WT) or following CRISPR-Cas9-mediated deletion of NUPR1\% (KO-NUPR1). (B) Analysis of ATF4 and CHOP expression following 6, 12 and $24 \mathrm{~h}$ TPS treatment in protein extracts of PANC-1 NUPR $1^{+/+}$or NUPR1 $1^{-/}$cells (KO Clone-1). (C) Quantification of A and B using ImageJ software. Mean band intensity plotted $\pm \operatorname{SEM}(n=3)$. Significant differences were calculated by two-way ANOVA with post hoc Sidak's test $(n=3)$. (C) Analysis by RT-qPCR of CHOP and GADD34 expression in NUPR1-deficient and matched control cells after treatment with $1 \mu \mathrm{M}$ TPS. Significant results between the two genotypes are reported in the graph $\left({ }^{* * *} p\right.$ $<0.0001,{ }^{* * *} p<0.001,{ }^{* *} p=0.0012,{ }^{*} p=0.04$ at $3,6,12$ and 24 hours respectively).

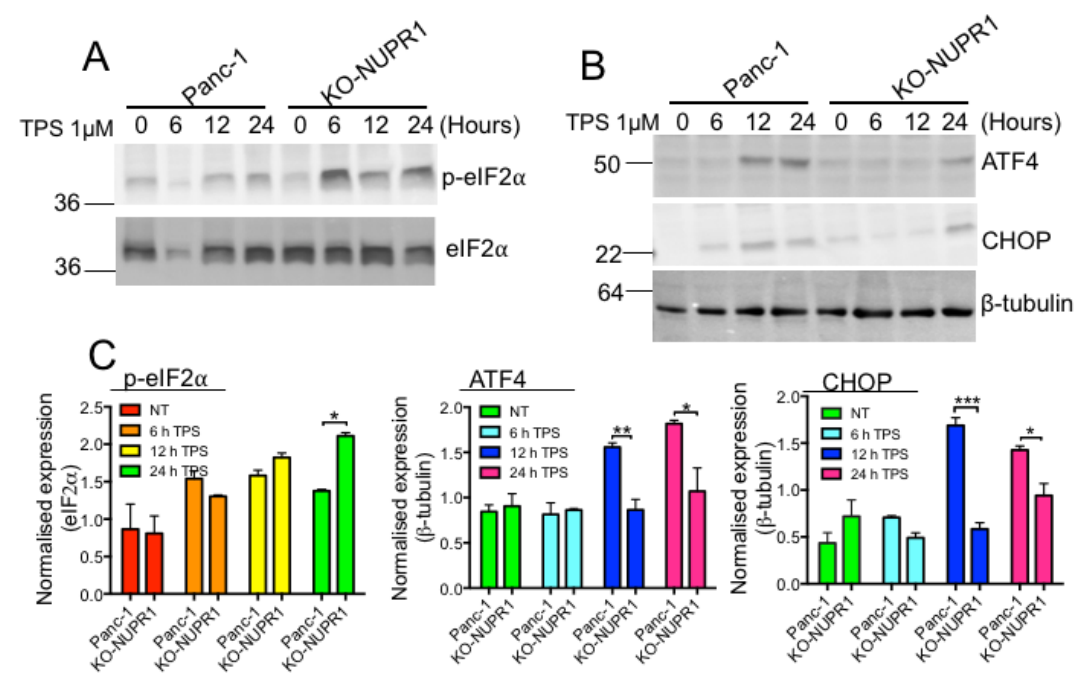

D
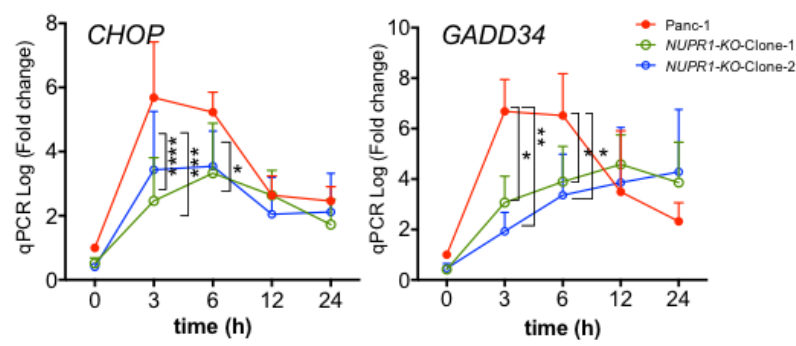


\section{Figure 7.}

\section{NUPR1 deletion reduces nascent protein production in pancreatic cancer cells after} stress induction. (A-C) Cultured PANC-1 cells or following CRISPR-Cas9-mediated deletion of NUPR1 (NUPR1 ${ }^{-/}$NUPR1-KO-Clone 1 and NUPR1-KO-Clone 2) were treated with vehicle or $1 \mu \mathrm{M}$ of TPS for one hour. After 3-6 or $16 \mathrm{~h}$, cells were incubated for 1 hour with OPpuromycin. Fluorescence was analysed by confocal microscopy and arbitrary fluorescent intensity (AFU) measured with image (D). Two-way ANOVA with a post hoc Sidak's test was used to determine statistical significance $\left({ }^{* *} p=0.001\right.$, $\left.{ }^{* * * *} p<0.001\right)$. (E) Flow cytometry of denovo protein synthesis measured with OP-puromycin. Cells were gated based on forward scatter (FSC) and side scatter (SSC) parameters. The mean fluorescence increases are reported on the $\mathrm{X}$ axis for WT or KO PANC-1 cells subjected to click chemistry of integrated OP-puromycin conjugated with FITC-azide. The Y-axis represents the cell count.
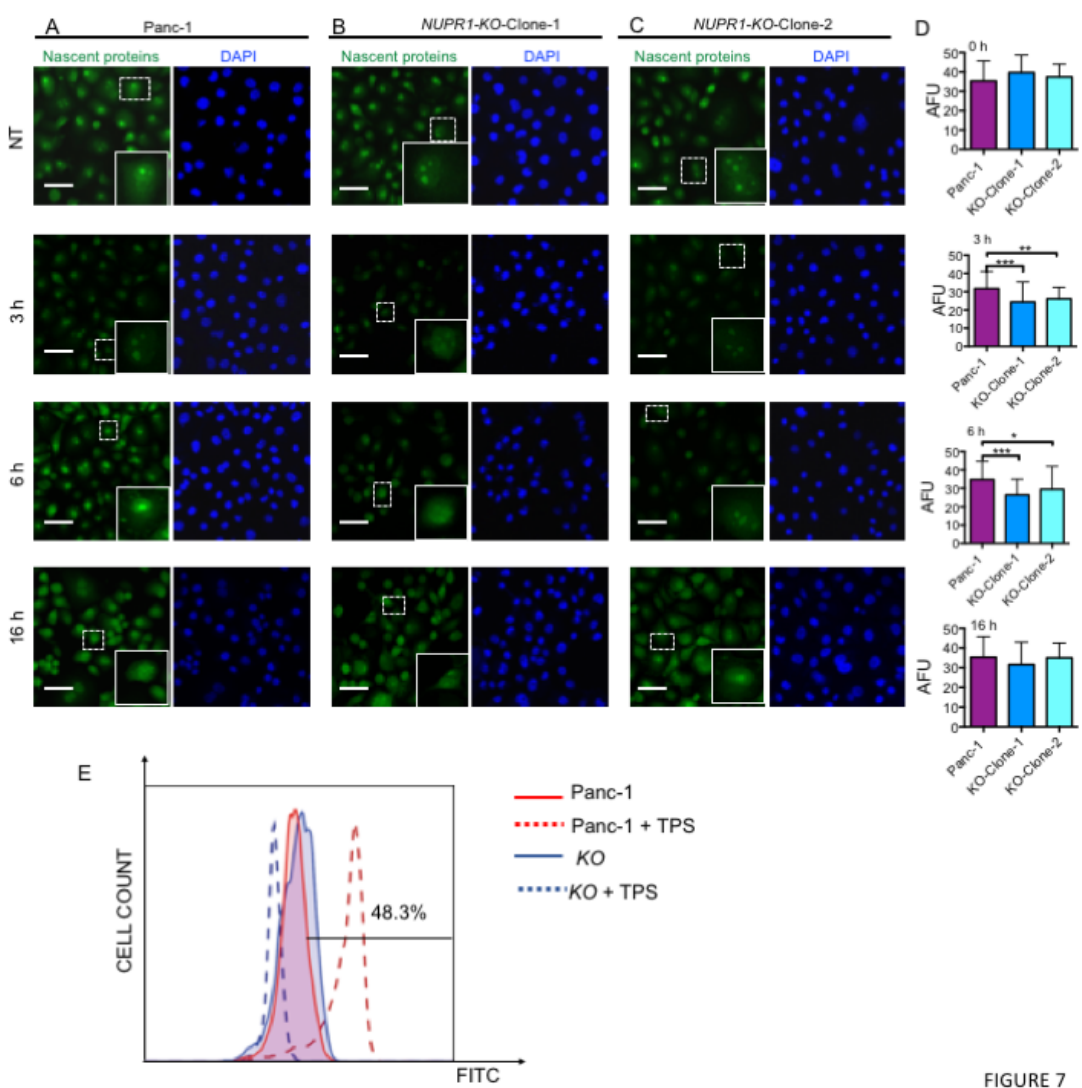


\section{Figure 8.}

The stress-induced protein NUPR1 orchestrates protein translation during ER-stress by interacting with elF2 $\alpha$ : NUPR1 by interacting with the elF2 $\alpha$ participates in the translational regulation after stress. In the absence of NUPR1 the phosphorylation of elF2 $\alpha$ is maintained for longer and all the expression of downstream regulators of ER is impaired.

NUPR1

NUPR1 KO

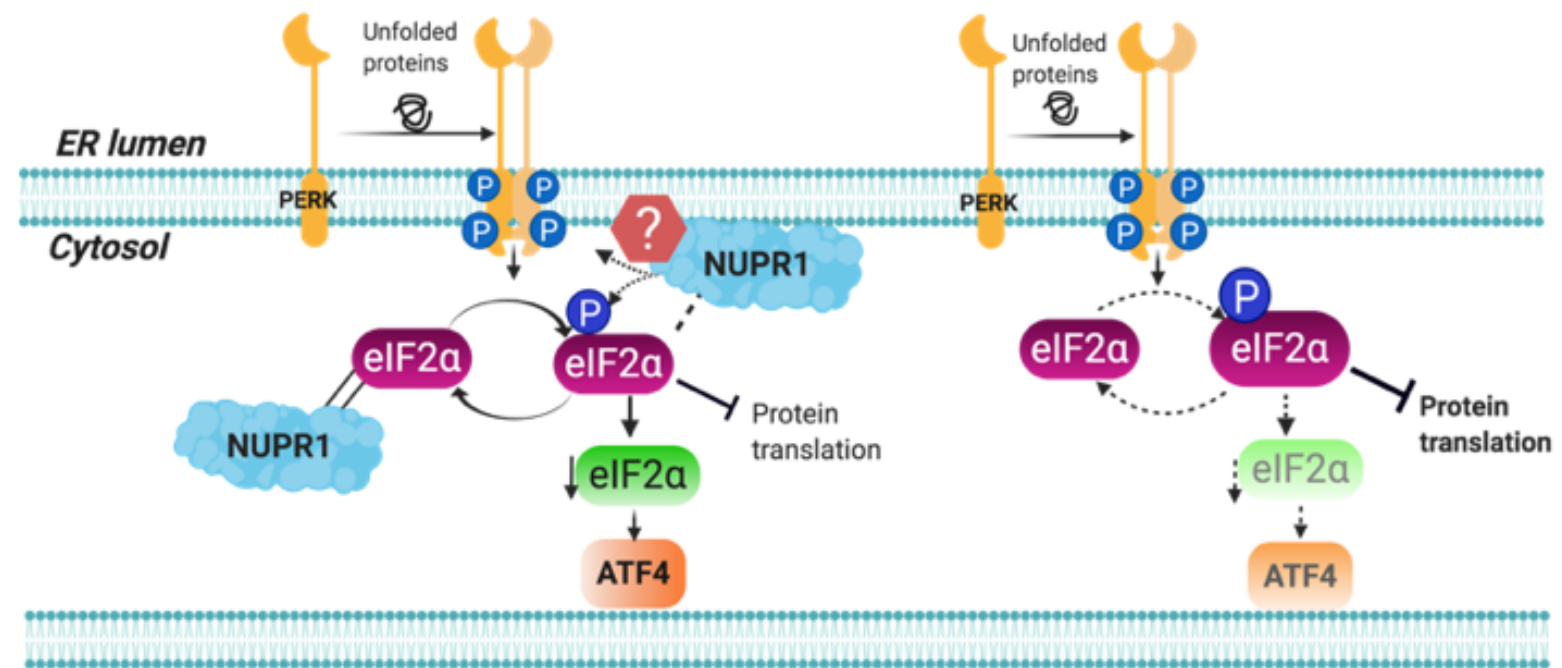

Nucleus 